\title{
Characterization of a novel glucocorticoid-resistant human B-cell acute lymphoblastic leukemia cell line, with AMPK, mTOR and fatty acid synthesis pathway inhibition
}

Yuanyuan $\mathrm{Li}^{1,2,3+}$, Chuan Zuo ${ }^{4+}$ and Ling Gu $\mathrm{G}^{1,2,33^{*}}$ (1)

\begin{abstract}
Background: Acquired glucocorticoid (GC) resistance remains the main obstacle in acute lymphoblastic leukemia (ALL) therapy. The aim of the present study was to establish a novel GC-resistant B-ALL cell line and investigate its biological characteristics.

Methods: A cell culture technique was used to establish the GC-resistant cell line from the parental cell, NALM-6. Molecular and cellular biological techniques including flow cytometry, MTT assay, western blotting, DNA fingerprinting analysis and whole transcriptome sequencing (WTS) were used to characterize the GC-resistant cell lines. Nude mice were used for xenograft studies.

Results: The GC-resistant cell line, NALM-6/HDR, was established by culturing NALM- 6 cells under hypoxia for 5 weeks with a single dexamethasone (Dex) treatment. We subcloned the NALM-6/HDR cell lines, and got 6 monoclone Dex-resistant cell lines, NALM-6/HDR-C1, C3, C4, C5, C6 and C9 with resistance index (RI) ranging from 20,00050,000. NALM-6/HDR and its monoclone cell line, NALM-6/HDR-C5, exhibited moderate (RI 5-15) to high resistance $(\mathrm{RI}>20)$ to Ara-c; low or no cross-resistance to L-Asp, VCR, DNR, and MTX (RI <5). STR analysis confirmed that NALM-6/ HDR and NALM-6/H were all derived from NALM-6. All these cells derived from NALM-6 showed similar morphology, growth curves, immunophenotype, chromosomal karyotype and tumorigenicity. WTS analysis revealed that the main metabolic differences between NALM-6 or NALM-6/H (GC-sensitive) and NALM-6/HDR (GC-resistant) were lipid and carbohydrates metabolism. Western blotting analysis showed that NALM-6/HDR cells had a low expression of GR and p-GR. Moreover, AMPK, mTORC1, glycolysis and de novo fatty acid synthesis (FAS) pathway were inhibited in NALM-6/ HDR when compared with NALM-6.
\end{abstract}

\footnotetext{
*Correspondence: guling@scu.edu.cn

†Yuanyuan Li and Chuan Zuo contributed equally to this work

${ }^{1}$ Laboratory of Hematology/Oncology, Department of Pediatrics, Key

Laboratory of Birth Defects and Related Diseases of Women and Children

(Sichuan University), Ministry of Education, West China Second University

Hospital, Sichuan University, No.20, Section 3, Renmin South Road,

Chengdu 610041, People's Republic of China

Full list of author information is available at the end of the article
}

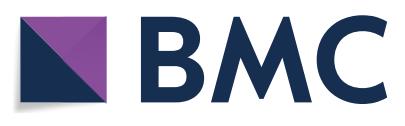

(c) The Author(s) 2021. Open Access This article is licensed under a Creative Commons Attribution 4.0 International License, which permits use, sharing, adaptation, distribution and reproduction in any medium or format, as long as you give appropriate credit to the original author(s) and the source, provide a link to the Creative Commons licence, and indicate if changes were made. The images or other third party material in this article are included in the article's Creative Commons licence, unless indicated otherwise in a credit line to the material. If material is not included in the article's Creative Commons licence and your intended use is not permitted by statutory regulation or exceeds the permitted use, you will need to obtain permission directly from the copyright holder. To view a copy of this licence, visit http://creativecommons.org/licenses/by/4.0/. The Creative Commons Public Domain Dedication waiver (http://creativeco mmons.org/publicdomain/zero/1.0/) applies to the data made available in this article, unless otherwise stated in a credit line to the data. 
Conclusions: NALM-6/HDR cell line may represent a subtype of B-ALL cells in patients who acquired GC and Ara-C resistance during the treatment. These patients may get little benefit from the available therapy target of AMPK, mTORC1, glycolysis and FAS pathway.

Keywords: Glucocorticoid, Resistance, Acute lymphoblastic leukemia, Hypoxia, Cell line

\section{Background}

Although contemporary chemotherapy regimens have improved the long-term survival rate of childhood acute lymphoblastic leukemia (ALL) to nearly $90 \%$ [1], the outcome of relapsed/refractory pediatric ALL is still extremely poor. Acquired drug resistance to chemotherapy, especially resistance to glucocorticoids (GCs), remains the main obstacle in ALL therapy [2, 3]. Many efforts were made to seek the mechanism of GC resistance and restore GC sensitivity, but showed little benefit to patients.

Drug-resistant cell lines that are established from drug-sensitive cell lines are the most useful models in tumor research, which have been used to investigate the mechanisms of drug resistance for nearly 50 years [4]. Traditionally, two methods, stepwise dose-escalation continuous exposure and high-concentration pulsatile exposure, are available to acquire drug resistance in cell lines [5]. There is a controversy regarding the traditional drug-exposure method for that the resistant phenotype obtained after a long time (6 16 months, or more) drug exposure and can only remain for several weeks or months after discontinuation of drug exposure, whether or not they can reflect the clinical setting [4]. Therefore, we constructed a novel and convenient method to establish GC resistant ALL cell lines from GC sensitive ALL cells by mimicking the hypoxic bone marrow (BM) microenvironment [6]. Compared to the traditional methods, the novel method has a high success rate, a single drug exposure, a short duration ( $5 \sim 6$ weeks), and a long maintenance of resistant phenotype without drug re-induction [6].

Hypoxia plays a central role in ALL progression and resistance to therapy [7]. Glycolysis-based metabolic reprogramming enhances multidrug resistance [8]. Previously, we established a T-ALL GC-resistant cell line, CEM-C7/HDR, and reported its biological characteristics [6]. T-ALL and B-ALL are highly heterogeneous disease and may have distinct mechanisms of GC resistance. To clarify the underlying mechanisms and therapeutic targets of hypoxia in relapsed/refractory B-ALL, we established a novel B-ALL GC-resistant cell line, NALM-6/HDR, derived from NALM-6 cell line, and studied the distinct biological characteristics of the cell line.

\section{Methods}

Cell line and culture conditions

The GC-sensitive B-ALL cell line, NALM-6 was purchased from Shanghai Institute Cell Resources Bank. NALM-6/HDR and NALM-6/H were established from NALM-6 as described previously [6]. All cells were cultured in RPMI 1640 (HyClone, Logan, UT, USA) supplemented with $10 \%$ fetal bovine serum (FBS; HyClone) at $37{ }^{\circ} \mathrm{C}$ under a humidified atmosphere with $5 \%$ carbon dioxide $\left(\mathrm{CO}_{2}\right)$ and $21 \%$ oxygen $\left(\mathrm{O}_{2}\right.$; normoxic condition).

\section{Reagents and antibodies}

Dexamethasone (DexA, Propidium iodide (PI), trypan blue, methylcellulose (MethoCult GFH4434) and 3-(4,5-dimethylthiazol-2-yl)-2,5-diphenyltetrazolium bromide (MTT) were obtained from Sigma-Aldrich (St. Louis, MO, US). The Annexin V-PI Kit was purchased from Roche (Mannheim, Germany). Antibodies to ATP-citrate lyase (ACLY), p-ACLY (Ser455), acetyl-CoA carboxylase (ACC), p-ACC (Ser79), fatty acid synthase (FASN), long-chain acyl-CoA synthetase 1 (ACSL1), acetyl-CoA synthetase (AceCS1), AMPK, p-AMPK (Thr172), Glut-1, HKII, LDHA, p-LDHA (Tyr10), 4E-BP1, p-4E-BP1 (Thr37/46), p70S6K, p-p70S6K (Thr389), glucocorticoid receptor (GR), and p-GR (Ser211) were obtained from Cell Signaling Technology (Beverly, MA, USA). Horseradish peroxidase (HRP)-conjugated donkey anti-rabbit antibody and HRP-conjugated sheep anti-mouse antibodies were obtained from Santa Cruz Biotech (Santa Cruz, CA, USA). The $\beta$-Actin and GAPDH antibody was purchased from Kangchen Bio-Tech (Shanghai, China).

\section{Subcloning of ALL cells}

As described previously [6], exponentially growing cells were seeded in 6 -well sterile plastic culture plates at a density of $5 \times 10^{2} / \mathrm{ml}$ in methylcellulose RPMI-1640 medium containing $0.9 \%$ methylcellulose and $10 \%$ FBS at $37{ }^{\circ} \mathrm{C}$ under a humidified atmosphere with $5 \% \mathrm{CO}_{2}$ and $21 \% \mathrm{O}_{2}$. Monoclonal cells were picked randomly on day 8 of the culture, and cultured in RPMI-1640 complete medium. 


\section{Cell growth and viability assay}

Exponentially growing cells were cultured in a 6-well sterile plastic culture plates for seven days. The number of viable cells was counted using heamocytometer and trypan blue staining every day. Doubling time (Td) of cells was calculated according to the following formula: $\mathrm{Td}(\mathrm{h})=\mathrm{t} \times \lg 2 / \lg \left(\mathrm{N}_{\mathrm{t}} / \mathrm{N}_{0}\right)$, where $\mathrm{t}$ is the time of continuous culture, $\mathrm{N}_{\mathrm{t}}$ is the final number of cells, and $\mathrm{N}_{0}$ is the initial number of cells.

Cell viability was evaluated by MTT assay. Briefly, cells were seeded in 96-well plates. Next, MTT with a final concentration of $0.5 \mathrm{mM}$ was added to the wells and incubated for $4 \mathrm{~h}$ at $37^{\circ} \mathrm{C}$. Then acidified SDS solution $(10 \%$ SDS in $0.01 \mathrm{M} \mathrm{HCl})$ were added to each well and incubated overnight at $37{ }^{\circ} \mathrm{C}$. Finally, the optical density was measured at $570 \mathrm{~nm}$ using a multiplate reader (Multiskan Spectrum, Thermo Electron Co., Waltham, MA, USA). Values were obtained by comparing the experimental cells with their respective controls. Mean values were calculated from triplicate cultures.

\section{Chemosensitivity assays}

The chemotherapeutic drugs, Dex, asparaginase (L-Asp), daunorubicin (DNR), vincristine (VCR), arabinoside (Ara-c), and methotrexate (MTX), were purchased from Sigma. All cells were treated with increasing concentrations of different drugs for $48 \mathrm{~h}$, followed by assessment of cell viability by MTT assay. The $\mathrm{IC}_{50}$ was calculated by linear interpolation.

\section{Cell cycle analysis}

Cells were harvested $48 \mathrm{~h}$ after treatment and fixed overnight in $70 \%$ ethanol at $4{ }^{\circ} \mathrm{C}$. The cells were then washed twice with PBS and stained with $5 \mu \mathrm{g} / \mathrm{ml}$ PI in the presence of DNAse-free RNAse (Sigma) for $30 \mathrm{~min}$ at room temperature. Then, the cell cycle distribution was analyzed by flow cytometry (Cytomics FC 500 and CXP \& Multicycle software, Beckman Coulter Inc., Miami, FL, USA).

\section{Immunophenotype analysis}

Antibodies against the following targets: HLA-DR, cCD3, CD3, CD79 $\alpha$, CD10, CD19, CD20, CD22, CD38, and CD45 (Becton Dickinson Inc., Franklin Lakes, NJ, USA) were used. Positivity for the antigens was determined using a FACSCalibur flow cytometer (Becton Dickinson Inc.).

\section{DNA fingerprinting analysis}

The identity of the NALM-6, NALM-6/HDR and NALM-6/H cell lines was checked using DNA fingerprinting. DNA was prepared from these cells using the Qiagen DNeasy Blood Kit (Qiagen), according to the instructions provided by the manufacturer. The following 22 highly polymorphic short tandem repeat (STR) loci were tested by a multiplex PCR: Amelogenin, CSF1PO, D13S317, D16S539, D5S818, D7S820, TH01, TPOX, vWA, Penta E, Penta D, D2S441, D2S1338, D3S1358, D6S1043, D8S1179, D10S1248, D12S391, D18S51, D19S433, D21S11 and FGA.

\section{Whole transcriptome sequencing (WTS) analysis}

Total RNA was extracted by Trizol reagent (Invitrogen, Thermo Fisher, Carlsbad, CA, USA) according to the manufacturer's instructions. RNA quality and purity were assessed by RNA 6000 Nano assay on Agilent 2100 Bioanalyzer (Agilent, Santa Clara, CA, USA). RNA-sequencing libraries were acquired on the BGISEQ-500 Platform in total and generated approximately $10.98 \mathrm{~Gb}$ per sample. After reads filtering, clean reads were mapped to the reference genome using HISAT. Then, gene expression levels for each sample were calculated with RSEM. Based on the gene expression level, the differentially expression genes (DEGs) between samples can be identified. PossionDis algorithms were used to detect the DEGs. With DEGs, we perform Gene Ontology (GO) classification, Kyoto Encyclopedia of Genes and Genomes (KEGG) pathway classification and functional enrichment.

\section{Western blotting analysis}

Briefly, cells $\left(10^{6}\right)$ were washed twice in cold PBS and then lysed by RIPA lysis buffer (Bio-Rad). Equivalent amounts of proteins were separated by $8-15 \%$ SDS-polyacrylamide gel electrophoresis and transferred to PVDF membranes ( 0.22 or $0.45 \mu \mathrm{m}$, Millipore). Immunoblots were assayed by using primary antibodies. HRP conjugated secondary antibodies were used for detection. The level of the $\beta$-Actin protein was used as a control for the amount of protein loaded into each lane.Proteins were visualized by incubation with ECL plus (Millipore). All experiments were conducted independently at least 3 times.

\section{Animal experiments}

Cultured $5 \times 10^{6}$ exponentially growing cells were subcutaneously injected into the right flanks of 6-week-old female BALB/c (nu/nu) nude mice (GemPharmatech Co., Ltd, Nanjing, China), and $0.1 \mathrm{ml}$ of PBS was injected into the left flanks as the control. Tumor size was measured by calipers every 2 days. The approximate tumor volume was calculated using the equation $\mathrm{V}=($ length $\times$ width $\times$ width $) / 2$. All animals were eartagged and monitored individually throughout the experiment. All animal care was in compliance with the 
guidelines established by the internal Institutional Animal Care and Use Committee and Ethics Committee of Sichuan University. Mice were euthanized by cervical dislocation after anesthetizing with a mixture of $100 \mathrm{mg} / \mathrm{kg}$ ketamine and $10 \mathrm{mg} / \mathrm{kg}$ xylazine via intraperitoneal injection. Then, the tumor mass was excised, fixed in $10 \%$ formalin, and routinely processed for paraffin embedding. Five-millimeter-thick sections were obtained and prepared for standard histopathological examination.

\section{Statistical analysis}

All assays were performed in triplicate, and data are expressed as mean values \pm SD. One-way ANOVA was used to compare two groups. A $p$-value $<0.05$ was considered to be significant.

\section{Results}

\section{Establishment of Dex-resistant NALM-6/HDR cell line} and its mono-clone cell line

NALM-6/HDR cell line was constructed following the method we reported previously [6]. Logarithmically growing NALM-6 cells were cultured under hypoxia condition for 5-6 weeks with or without dexamethasone (Dex) treatment. Then, the cells were cultured continuously under normoxic condition and constructed a stable resistant cell line, NALM-6/HDR (Fig. 1a). The $\mathrm{IC}_{50}$ and RI of Dex in the NALM-6/HDR cells were $55-70 \mu \mathrm{M}$ and 25,000-30,000, respectively [6]. All NALM-6/HDR subclones were resistant to Dex with $\mathrm{IC}_{50}$ and $\mathrm{RI}$ ranging from 50 to $125 \mu \mathrm{M}$ and 25,000-50,000, NALM-6/HDRC5 cells were the most resistant cells to Dex among the monoclonal cell lines (Fig. 1b). Unlike the CEM-C7/H [6], the control group, NALM-6/H, which was cultured under the hypoxic condition with no Dex treatment, did not get Dex resistance. The $\mathrm{IC}_{50}$ of Dex in the NALM6, NALM-6/H and its monoclonal cells was 0.002$0.005 \mu \mathrm{M}$. GC-resistant cells may get cross-resistance to other drugs [9]. Our results showed that NALM-6/HDR and its monoclonal cell line, NALM-6/HDR-C5, exhibited very high resistance to Dex, moderate (RI 5-15) to high resistance (RI $>20)$ to Ara-c (Fig. 1f, h); low or no cross-resistance to L-Asp, DNR, VCR, and MTX $(\mathrm{RI}<5)$ (Fig. 1c-h). Although $\mathrm{IC}_{50}$ of L-Asp, DNR, VCR and MTX were higher in NALM-6/H than in NALM-6, the RI only ranged from 1.43 to 2.04 , which indicated that hypoxia treatment only would not induce drug resistance in NALM-6.

\section{Morphological and biological characteristics of NALM-6/ HDR cells}

The NALM-6/HDR and NALM-6/HDR-C5 cells were grown in suspension as single cells, and Wright-Giemsa staining showed almost no differences in morphology among the cell lines originated from NALM-6 (Fig. 2a, b). All the cells lines showed similar percentages of $G_{0} / G_{1}, S$ and $G_{2} / M$ phase cells, with no statistically significant differences observed $(P>0.05)$ (Fig. 2c). They also exhibited similar growth curves (Fig. 2d). The cell lines all stably proliferated in RPMI-1640 medium containing 10\% FBS with population doubling times of $19 \sim 22 \mathrm{~h}$. Chromosomal analysis showed that the karyotype of NALM-6/ HDR was 46, XY, t(5;12)(q33;p13), t(7;19)(q11.1;p13.3), the same as NALM-6 (Fig. 2e). NALM-6/HDR and NALM-6 displayed identical immunophenotype with CD10, CD19, CD22, cCD79 $\alpha$ and HLA-DR positive (Additional file 1: Fig. S1). STR analysis confirmed that NALM-6/HDR and NALM-6/H were all derived from NALM-6 (Table 1).

\section{KEGG pathways analysis of DEGs between NALM-6/HDR and NALM-6}

To elucidate the underlying mechanisms of GC resistance in NALM-6/HDR, the WTS together with integrated bioinformatics analysis were conducted. Venn diagram was used to display expressed gene between samples, NALM-6, NALM-6/H, and NALM-6/HDR, shown as Additional file 2: Fig. S2a. Summary of DEGs was shown in Additional file 2: Fig. S2b. The results showed a total of 341 DEGs between the NALM-6 and NALM-6/HDR cell lines. Among these, 140 up-regulated and 201 downregulated DEGs were identified (Additional file 2: Fig. $\mathrm{S} 2 \mathrm{~b}$ ), involving numerous signaling pathways. Metabolic reprogramming is increasingly recognized as a fundamental hallmark of cancer [10]. KEGG pathway classification analysis showed that the main metabolic differences between NALM-6 or NALM-6/H (GC-sensitive) and NALM-6/HDR (GC-resistant) were lipid and carbohydrates metabolism (Fig. 3, Additional file 3: Fig. S3). NALM-6 and NALM-6/H showed a relative similar metabolic character (Fig. 3).

\footnotetext{
(See figure on next page.)

Fig. 1 Establishment and resistance characteristics of NALM-6/HDR and its monoclone cell lines. a Flow chart for constructing the GC-resistant NALM-6/HDR cell lines. $\mathbf{b} \mid C_{50}$ and RI of the subclones of NALM-6/HDR cells to Dex. Cells were cultured with increasing concentrations of Dex for $48 \mathrm{~h}$. Cell viability was evaluated by MTT assays. The IC ${ }_{50}$ values were calculated by linear interpolation. Experiments were performed in triplicate. c-g IC50 of NALM-6, NALM-6/HDR, NALM-6/HDR-C5, and NALM-6/H cells to L-Asp, DNR, VCR, Ara-c, and MTX. Cells were cultured with increasing concentrations of different drugs for $48 \mathrm{~h}$. Cell viability was evaluated by MTT assays. The IC50 values were calculated by linear interpolation. Experiments were performed in triplicate. $\mathbf{h}$ RI of NALM-6/HDR, NALM-6/HDR-C5, and NALM-6/H cells to L-Asp, DNR, VCR, Ara-C, and MTX
} 
A

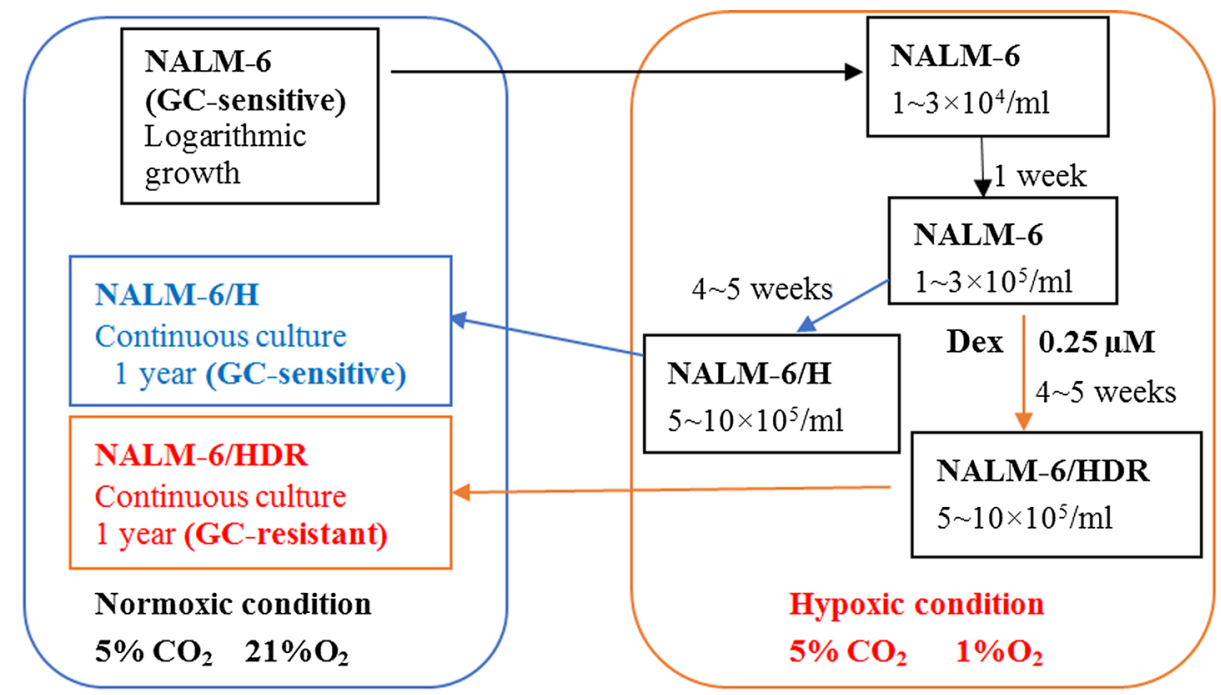

B

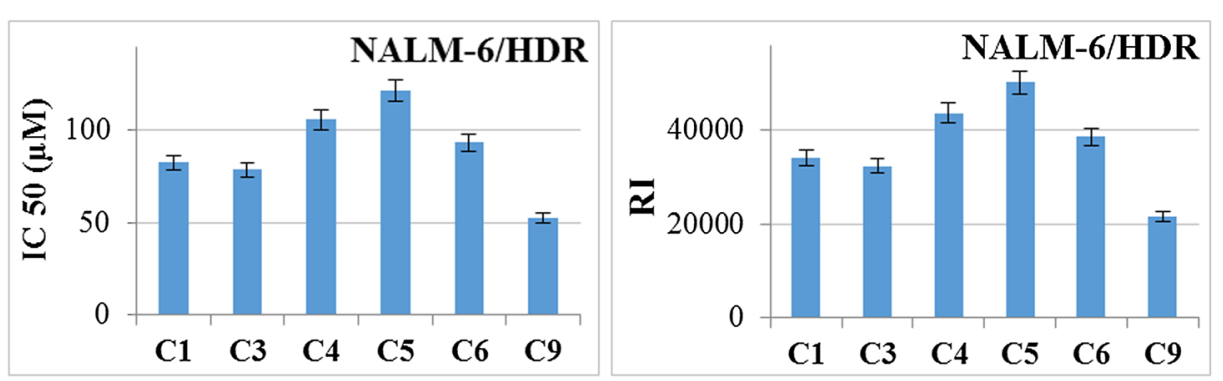

C

D DNR (nM)
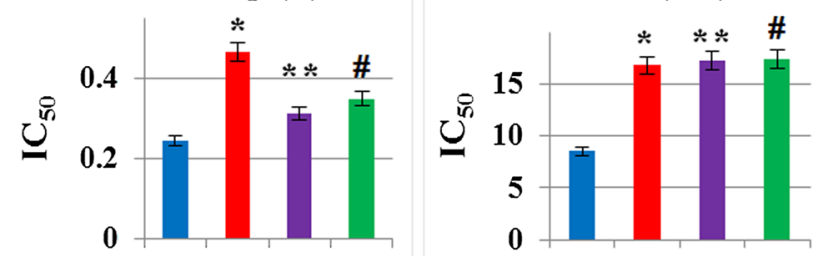

E VCR (nM)
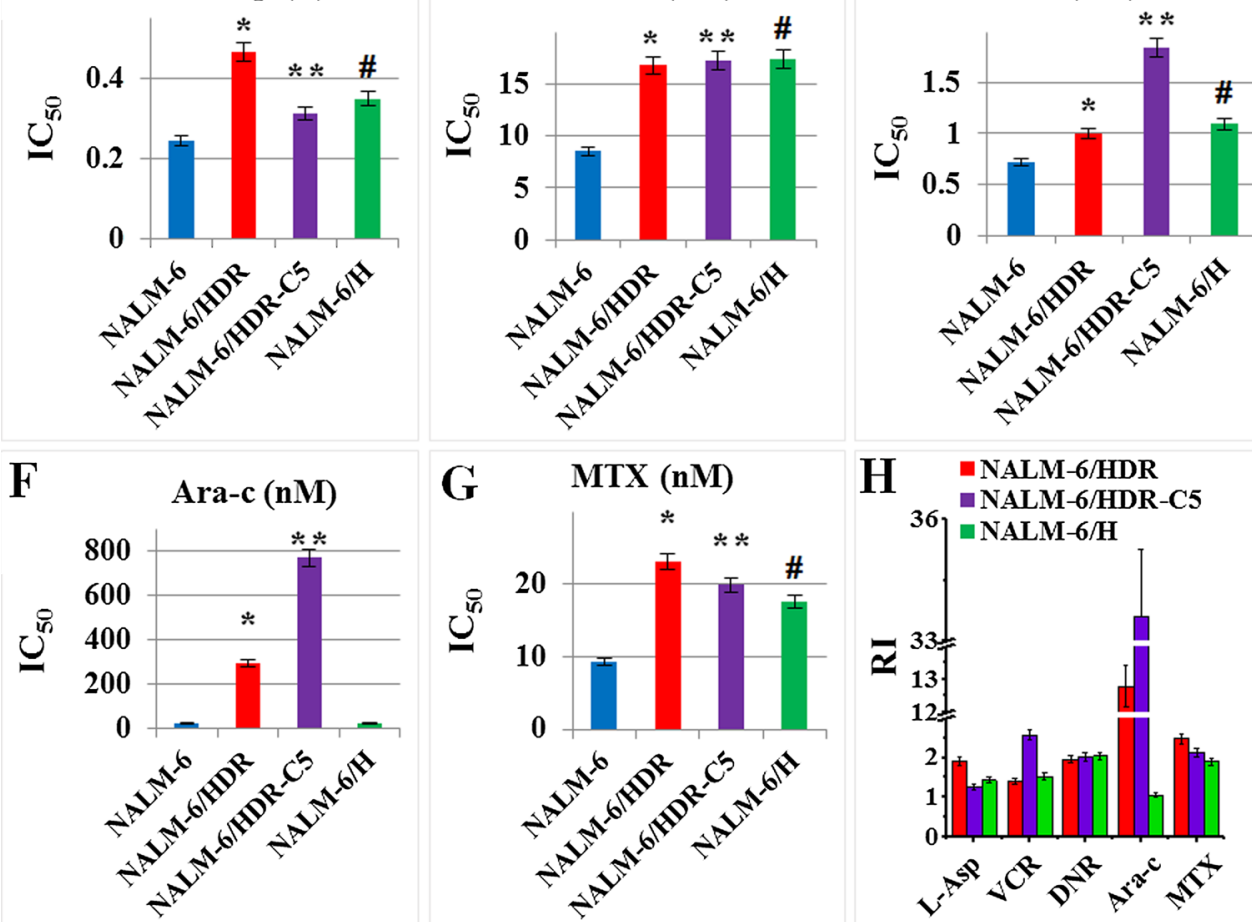

Fig. 1 (See legend on previous page.) 


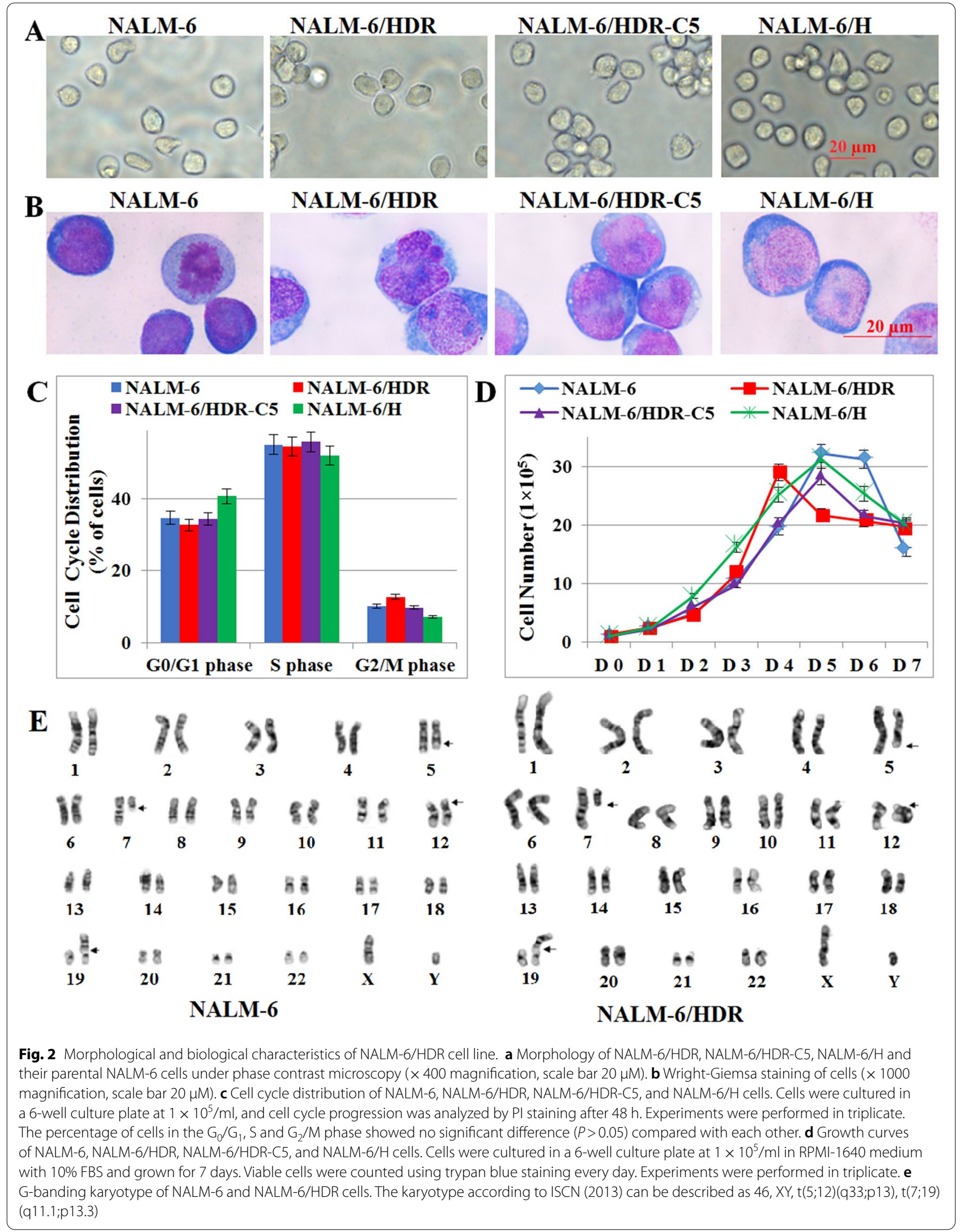


Table 1 STR analysis of NALM-6, NALM-6/HDR and NALM-6/H

\begin{tabular}{lllll}
\hline & NALM-6* & NALM-6 & NALM-6/HDR & NALM-6/H \\
\hline Amelogenin & $X, Y$ & $X, Y$ & $X, Y$ & $X, Y$ \\
CSF1PO & 12,12 & 12,13 & 12,12 & 12,12 \\
D13S317 & $8,9,12$ & $8,9,11,12$ & 8,12 & 8,12 \\
D16S539 & $9,10,11$ & $9,10,11$ & 9,11 & 9,11 \\
D5S818 & $10,11,12$ & 11,12 & 11,12 & 11,12 \\
D7S820 & $8,9,10$ & 8,10 & 8,10 & 8,10 \\
TH01 & 8,9 & 8,9 & 8,9 & 8,9 \\
TPOX & 8,10 & 8,10 & 8,10 & 8,10 \\
vWA & 15,16 & 15,16 & 15,15 & 15,15 \\
Penta E & ND & 11,11 & 11,11 & 11,11 \\
Penta D & ND & 8,14 & 8,14 & 8,14 \\
D2S441 & ND & 10,14 & 10,14 & 10,14 \\
D3S1358 & ND & 16,17 & 16,17 & 16,17 \\
D6S1043 & ND & 11,11 & 11,11 & 11,11 \\
FGA & ND & 22,23 & 22,23 & 22,23 \\
\hline
\end{tabular}

*STR profile of NALM- 6 was extracted from the database of DSMZ cell bank

\section{Expression of proteins associated with fatty acid metabolism}

Changes in lipid metabolism, in particular increased de novo fatty acid synthesis (FAS), are recognized as one of the key hallmarks in several cancer cells $[11,12]$. Besides, FASN overexpression has shown to be associated with poor prognosis and resistance to chemotherapy $[12,13]$. However, in accordance with the results of transcriptome analysis, the results of western blotting showed that the expression of ACLYp-ACLY, ACC, p-ACC, FASN, ACSL1 and AceCS1 were all lower in NALM-6/HDR than in NALM-6 (Fig. 4a, b), which means that NALM-6/HDR cells got a relative low FAS metabolism phenotype accompanying with GC-resistance feature. NALM-6/H showed a relative similar FAS metabolism phenotype with NALM-6, except for a lower expression of ACSL1 and AceCS1 and a higher expression of FASN (Fig. 4a, b). The results hinted that only the GC-resistant NALM-6/HDR cells got a relative low FAS metabolism phenotype.

\section{Global and overview maps Energy metabolism Metabolism of cofactors and vitamins Amino acid metabolism \\ Carbohydrate metabolism \\ Glycan biosynthesis and metabolism Lipid metabolism Nucleotide metabolism Metabolism of other amino acids Xenobiotics biodegradation and metabolism}

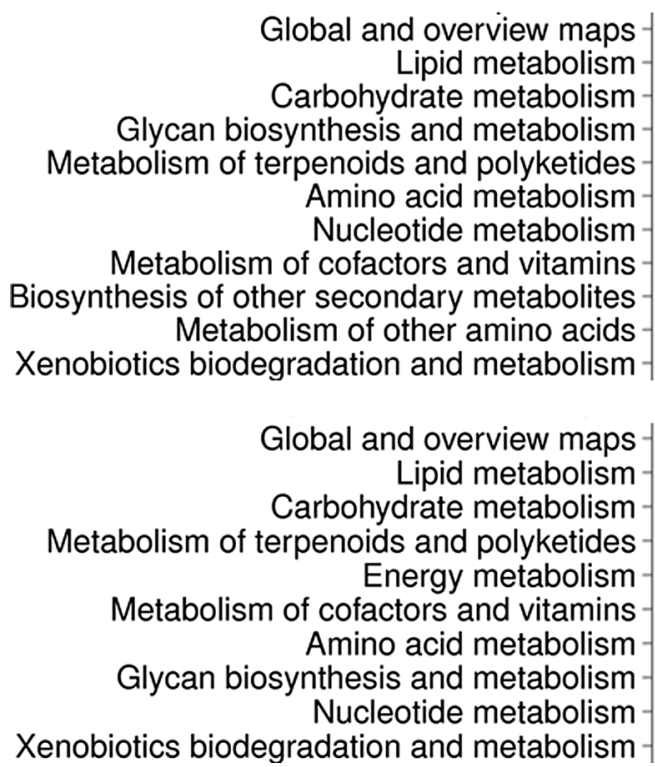

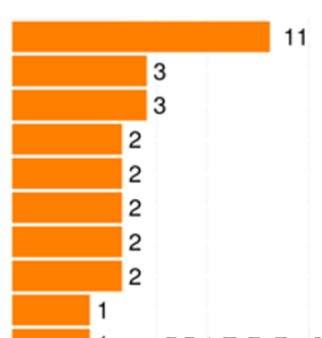

1 NALM-6 vs NALM-6/H

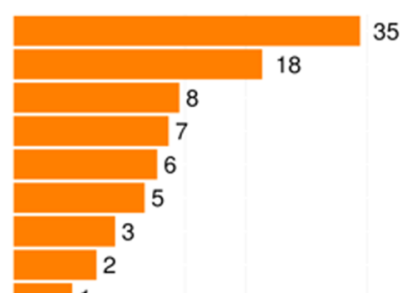

NALM-6 vs NALM-6/HDR

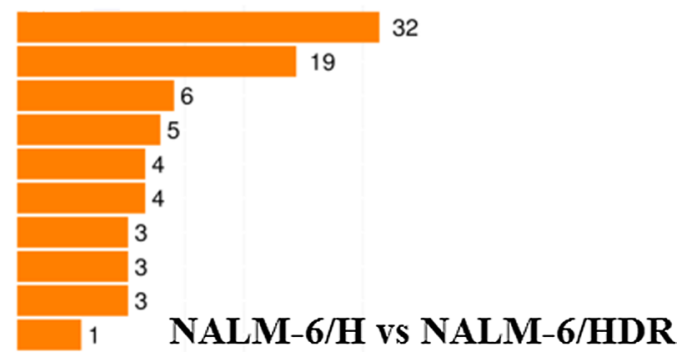

Fig. 3 Pathway classifications of DEGs in Metabolism. X axis represents number of DEGs. Y axis represents functional classification in metabolism of KEGG pathway. The main metabolic differences between NALM-6 or NALM-6/H (GC-sensitive) and NALM-6/HDR (GC-resistant) were lipid metabolism and carbohydrates metabolism 


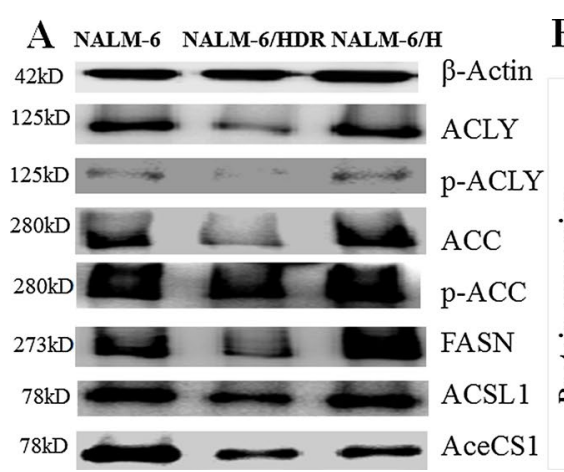

\section{B}

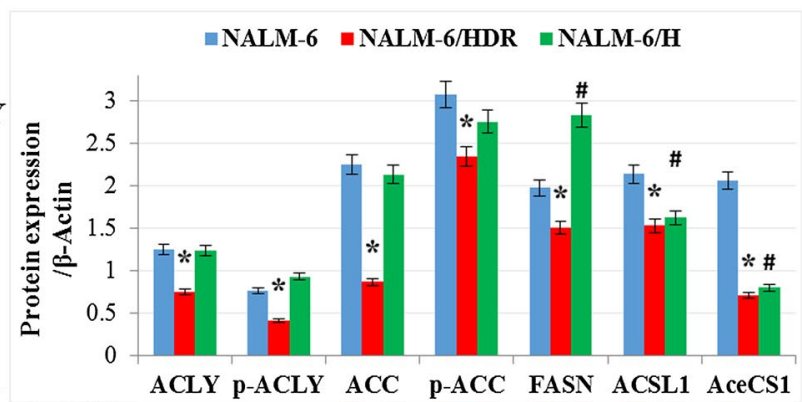

Fig. 4 Expression of proteins associated with fatty acid metabolism. a Cells were lysed, and extracts were analyzed by western blotting for ACLY, p-ACLY (Ser455), ACC, p-ACC(Ser79), FASN, ACSL1 and AceCS1. $\beta$-Actin was used as an internal control. b Bar graphs show the ratio of proteins to $\beta$-Actin. For all experiments, values of triplicate experiments are shown as the mean \pm SD. *: $p<0.01$ versus NALM- 6 . : $p<0.01$ versus NALM-6

Expression of proteins associated with glucose metabolism Hypoxia may induce a metabolic switch in energy production, which is characterized by an increase in glycolysis phenotype in cancer cells [14]. We generated NALM-6/HDR cell line from culturing under hypoxia condition for 5 weeks. Therefore, we detected the expression of the energy sensor proteins, AMPK and p-AMPK, and glycolysis-associated proteins. Consistent with the results of CEM-C7/HDR [6], the expression of AMPK and p-AMPK in NALM-6/HDR were both lower than that in NALM-6 $(\mathrm{p}<0.01)$ (Fig. 5a). In NALM-6/H, the expression of $\mathrm{p}$-AMPK was lower than that in NALM-6, and the AMPK expression showed no significant difference ( $p>0.05$ ) (Fig. 5a). Moreover, the expression of HKII was reduced $(\mathrm{p}<0.01)$; LDHA were induced $(\mathrm{p}<0.01)$; Glut-1, GAPDH and p-LDHA showed no significant difference $(p>0.05)$ in NALM-6/HDR when compared with NALM-6 (Fig. 5b). In NALM-6/H, Glut-1, LDHA

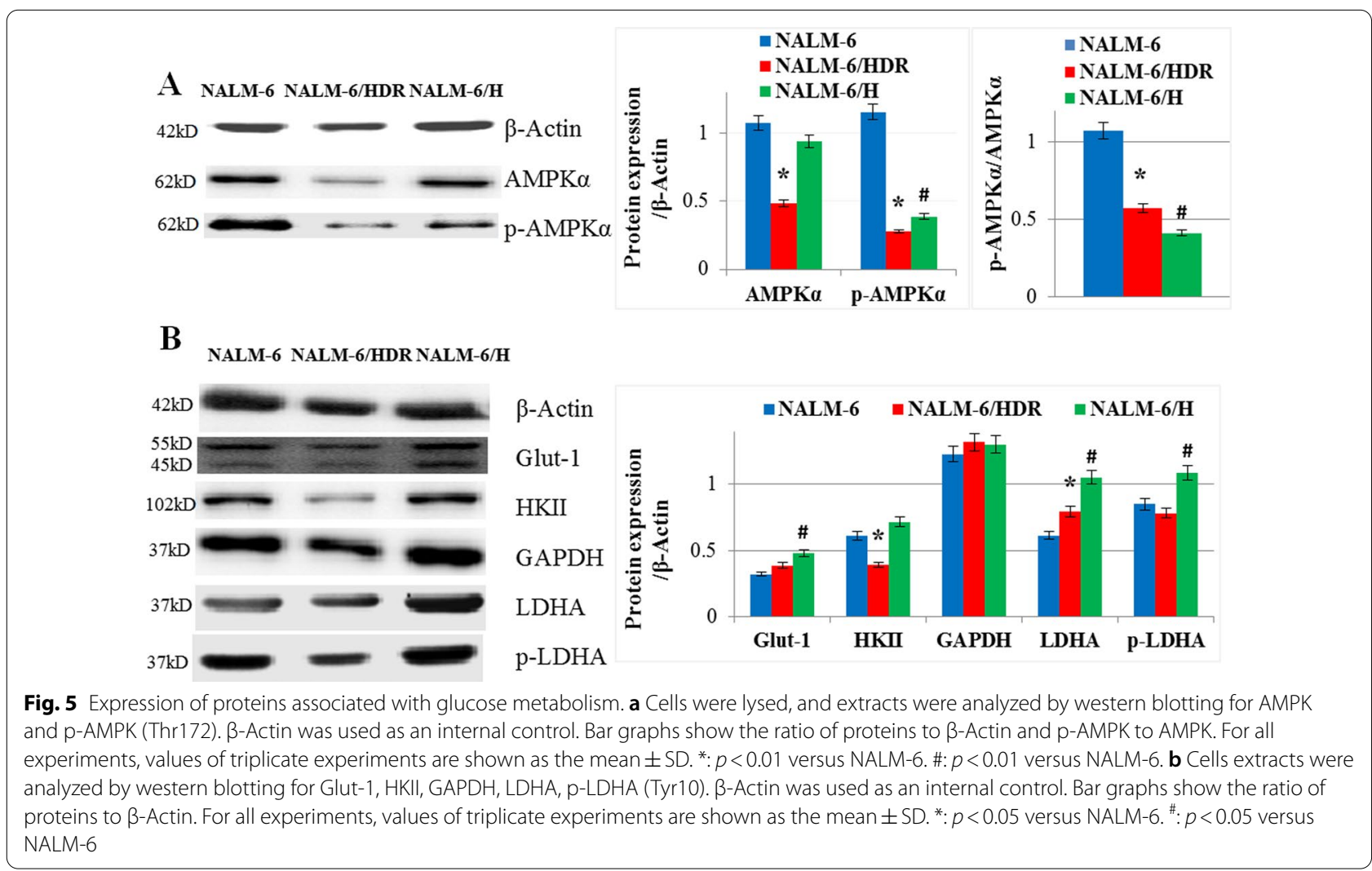


A NALM-6 NALM-6/HDR NALM-6/H

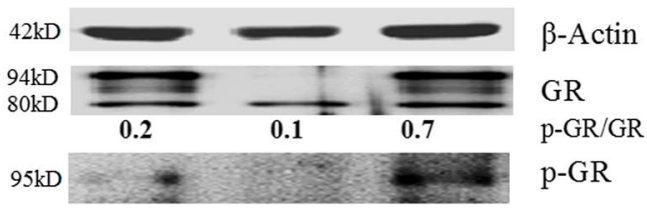

B NALM-6 NALM-6/HDR NALM-6/H

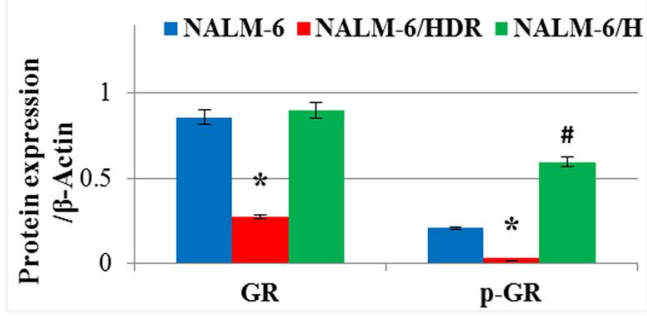

$\beta$-Actin

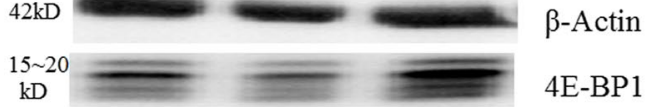
0.8 1.0 p-4E-BP1/4E-BP1

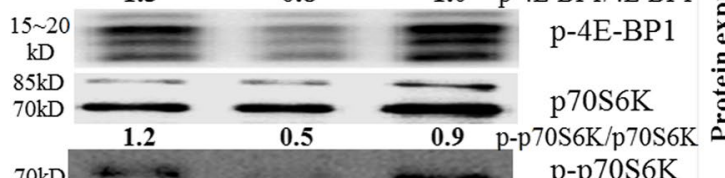
p-p70S6K

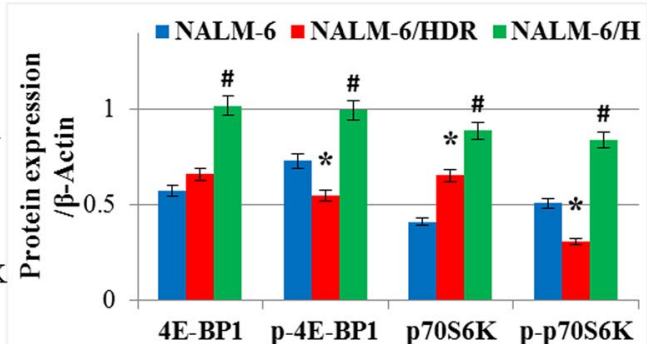

Fig. 6 Expression of proteins associated with GC resistance in NALM-6/HDR. a Cells extracts were analyzed by western blotting for GR and p-GR (Ser211). $\beta$-Actin was used as an internal control. Bar graphs show the ratio of proteins to $\beta$-Actin. For all experiments, values of triplicate experiments are shown as the mean \pm SD. ${ }^{*}: p<0.01$ versus NALM-6 and NALM-6/H. \#: $p<0.01$ versus NALM-6 and NALM-6/HDR. b Cells extracts were analyzed by western blotting for 4E-BP1, p-4E-BP1 (Thr37/46), p70S6K, and p-p70S6K (Thr389). $\beta$-Actin was used as an internal control. Bar graphs show the ratio of proteins to $\beta$-Actin. For all experiments, values of triplicate experiments are shown as the mean \pm SD. ${ }^{*}: p<0.01$ versus NALM-6 and NALM-6/H. \#: $p<0.01$ versus NALM-6 and NALM-6/HDR

and $\mathrm{p}$-LDHA were induced $(\mathrm{p}<0.01)$ when compared with NALM-6; HKII and GAPDH showed no difference ( $p>0.05)$ (Fig. 5b); HKII, LDHA and $p$-LDHA were induced $(\mathrm{p}<0.01)$ when compared with NALM-6/HDR. The results showed NALM-6/HDR got a relative low glycolysis phenotype when compared to NALM- $6 / \mathrm{H}$.

\section{Expression of proteins associated with GC resistance in NALM-6/HDR}

Loss of GR expression plays a key role in GC resistance and is associated with poor prognosis in leukemia patients $[15,16]$. As shown in Fig. 6a, the expression of GR and p-GR (Ser211) were significantly lower in NALM-6/HDR cells than that in NALM-6 and NALM$6 / \mathrm{H}$ cells $(\mathrm{p}<0.01)$. However, hypoxia treatment only induced the expression of $\mathrm{p}-\mathrm{GR}$ and the ratio of $\mathrm{p}-\mathrm{GR}$ to GR in NALM-6/H $(\mathrm{p}<0.01)$ (Fig. 6a). Dysregulated activation of PI3K-Akt-mTOR pathway may relate to the chemotherapeutic resistance, including GC resistance, in hematological malignances $[17,18]$. The expression of the two main downstream effectors of mTOR, 4E-BP1 and $\mathrm{p} 70 \mathrm{~S} 6 \mathrm{~K}$, and their phosphorylated status $\mathrm{p}-4 \mathrm{E}-\mathrm{BP} 1$ (Thr37/46) and p-p70S6K (Thr389), were all induced in NALM-6/H, compared with NALM-6 and NALM-6/ HDR cells $(\mathrm{p}<0.05)$ (Fig. $6 \mathrm{~b})$. The ratio of $\mathrm{p}-4 \mathrm{E}-\mathrm{BP} 1$ (Thr37/46) to 4E-BP1 and p-p70S6K (Thr389) to p70S6K were reduced in NALM-6/H, compared with NALM-6 (Fig. 6b). In NALM-6/HDR, 4E-BP1 showed no significant difference $(\mathrm{p}>0.05)$; $\mathrm{p} 70$ S6K increased $(\mathrm{p}<0.01)$; p-4E-BP1 (Thr37/46) and p-p70S6K (Thr389) decreased $(\mathrm{p}<0.05)$ when compared with NALM- 6 . The ratio of p-4E-BP1 (Thr37/46) to 4E-BP1 and p-p70S6K (Thr389) to $\mathrm{p} 70 \mathrm{S6K}$ were reduced in NALM-6/HDR $(\mathrm{p}<0.05)$, compared with NALM-6 and NALM-6/H. The results showed that the inhibition of GR and mTOR pathway might be a main character of NALM-6/HDR.

\section{The tumorigenicity of NALM-6/HDR cells}

In an in vivo transplantation test, subcutaneous injection of NALM-6 and NALM-6/HDR resulted in the

(See figure on next page.)

Fig. 7 Tumorigenicity of NALM-6/HDR cells. a The growth curve of subcutaneous tumors in nude mice. All animal procedures were carried out in accordance with the guidelines established by the internal Institutional Animal Care and Use Committee and Ethics Committee guidelines of Sichuan University. $\mathbf{b}$ HE staining of the tumors derived from NALM- 6 and NALM-6/HDR showed that the xenografts were composed of leukemia cells and blood vessels. Original magnification: $\times 400$ magnification. (c-f) On IHC staining, both xenografts expressed GR, Glut-1, HKII, and 4E-BP1 proteins, with a relative lower expression of GR and HKII in NALM-6/HDR than that in NALM-6 
A

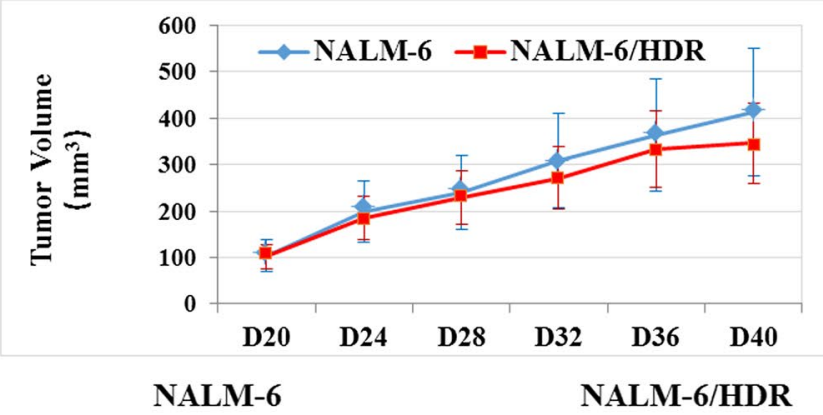

B
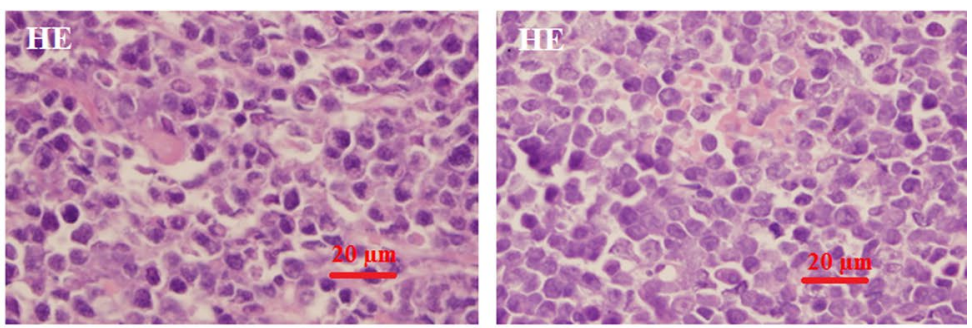

C
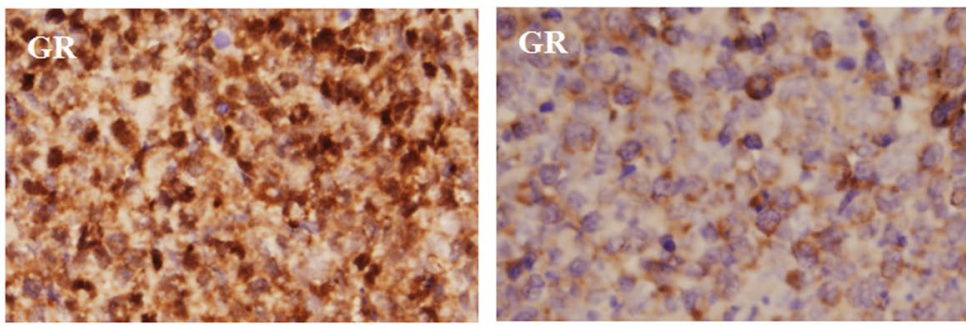

D
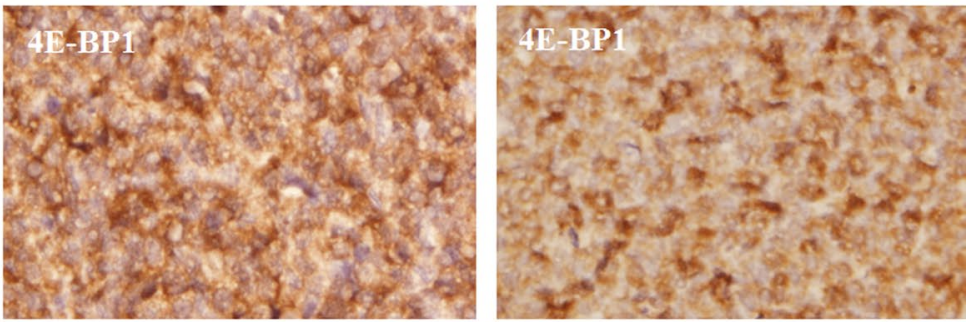

E
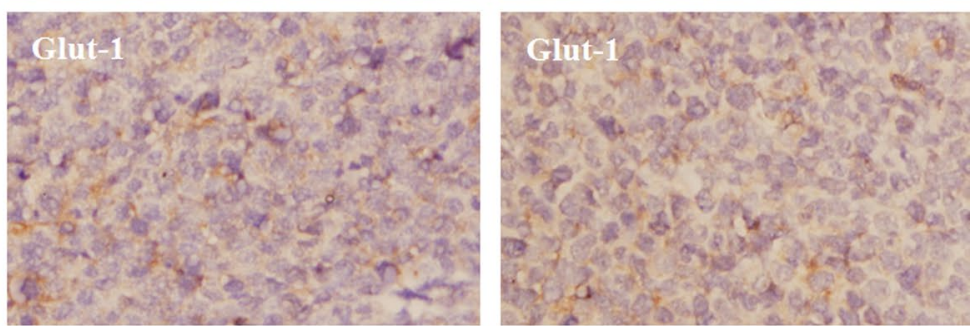

F
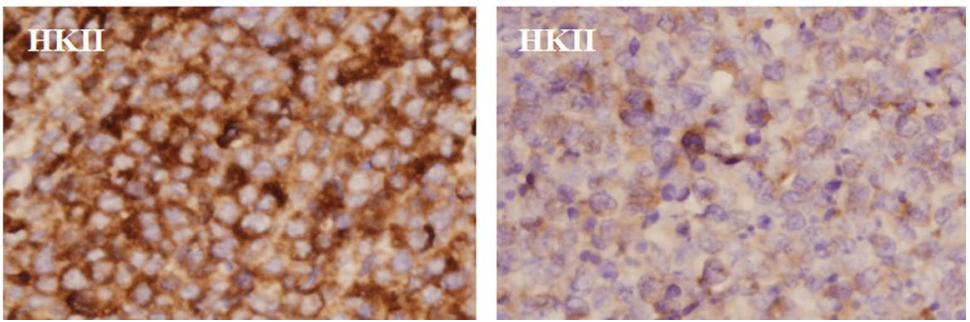

Fig. 7 (See legend on previous page.) 
development of tumors in 7 of 12 mice (58\%). After 40 days, the mean volume of the tumors generated by subcutaneous injection with NALM-6 and NALM-6/ HDR were $413.2 \pm 140.0 \mathrm{~mm}^{3}(\mathrm{n}=4)$ and $346.9 \pm 102.7$ $\mathrm{mm}^{3}(\mathrm{n}=3)$, respectively (Fig. 7a). Hematoxylin and eosin (HE) staining indicated that the tumor masses were composed of leukemia cells (Fig. 7b). Immunohistochemistry (IHC) staining showed that the expression of GR, Glut-1, HKII, and 4E-BP1 proteins were in consistent with the results of western blotting, the expression of GR and HKII were decreased in NALM-6/HDR obviously (Fig. 7c-f).

\section{Discussion}

Over the last century, studies on patient-derived cancer cell lines have provided crucial insights into the biological processes in tumorigenesis and high-throughput screening for drug development [19]. Molecular alterations that are detected in a drug-resistant cell line, when compared to its drug-sensitive counterpart, can suggest molecular mechanisms underlying drug resistance. Drug resistant cell lines, constructed by the traditional drugexposure method, have been used in the research on the mechanisms of drug resistance for 50 years, which created a new problem whether or not they can reflect the clinical setting and resole the clinical problems [4]. Furthermore, drugs at a high concentration can kill all parental cells, which make construction of a highly resistant cell line difficult and make construction of a resistant cell line from a highly drug-sensitive cell line more difficult. Therefore, we established a method that matches the manner in which chemotherapy is administered to patients [6]. NALM-6 is highly sensitive to GC, and it is one of the 5 pre-B-ALL cell lines in 100 authenticated leukemia-lymphoma cell lines $[20,21]$. Meanwhile, NALM- 6 was widely used in the researches on ALL and was recommended as a classic/reference cell line of BCPALL [21]. Fortunately, via the novel method, we established the GC-resistant B-ALL cell line, NALM-6/HDR, which is highly resistant to GC with a moderate to high cross-resistant to Ara-C, and shows similar morphology, growth curves, immunophenotype, chromosomal karyotype and tumorigenicity with its parental cell line, NALM-6, and the control cell line, NALM-6/H.

GCs specifically induce apoptosis in malignant lymphoblasts and are thus pivotal in the treatment of lymphoid malignancies, especially in ALL [22]. However, GC resistance remains one of the strongest predictors of relapse in ALL and accounts for most of the treatment failures $[2,3]$. Despite decades of clinical practice and laboratory investigation, the exact molecular mechanisms contributing to GC resistance has not been fully uncovered. GCs induce apoptosis by combined with GR and translocated to nucleus and then interaction with GC response elements (GRE), and then activating or suppression transcription of target genes [23, 24]. Initially, most studies showed that low GR protein levels plays a crucial role in $\mathrm{GC}$ resistance $[15,16,23-26]$, but then the conclusion was rebutted by the results that high GR expression was found also in GC-resistant ALL cells [23, 24, 27, 28]. Anyway, almost all of the GC sensitive ALL cells had a high expression of GR [23]. Recently, loss of GR expression renewed attention on the exploration of GC resistance $[15,16,23]$. Our results showed that NALM-6/ HDR expressed a lower GR and p-GR (Ser211) compared to NALM-6 and NALM-6/H in vivo and in vitro. The same, CEM-C7/HDR cells, which were constructed using the same method, showed a low GR expression also [6]. These data implicate reduced GR expression as an important cause of acquired GC resistance.

However, the mechanism of GC resistance is much more complicated than a GR alternation. The level of the GRs expression among ALL patients and derived cell lines appears to be highly heterogeneous [23]. There are several additional mechanisms, triggered by alterations of different signaling pathways, including Notch, Il7R/JAK/ STAT, RAS/MEK/ERK, PTEN/PI3K/AKT/mTOR and $\mathrm{Ca}^{2+}$ signaling, which cause the metabolic reprogramming, with an enhanced level of glycolysis and oxidative phosphorylation, apoptosis resistance, and multidrug resistance [23]. According to the clinical set, hypoxic stress play a pivotal role in inducing GC resistance in ALL cells $[6,7,29,30]$. Generally, tumor cells respond to hypoxic stress by upregulating various genes involved in glucose uptake, glycolysis, and angiogenesis, to maintain the cellular metabolic demands; at the same time, translation of "unnecessary" proteins are deregulated to prevent the accumulation of stress-induced unfolded and/ or misfolded proteins[29, 31]. Leukemia cells were originated from $\mathrm{BM}$ and grown in the hypoxic microenvironment, and then released to the peripheral blood with adequate oxygen. Therefore, leukemic cells, living in both hypoxic and normoxic microenvironments, may have distinct metabolic response to hypoxia from solid tumor cells. A real-time metabolism study on chronic lymphocytic leukemia (CLL) cells showed that circulating CLL cells were primed for hypoxia and showed the same adaptive response upon secondary exposure to hypoxia [32]. Similarly, our results showed that NALM-6/H had a little difference in metabolism when compared to NALM-6. The expression of p-AMPK even decreased in NALM-6/H when compared to NALM-6, which means that there was almost no energy metabolic problem for NALM-6 upon exposure to hypoxia. However, the GCresistant NALM-6/HDR showed an obvious difference in 
metabolism, especially in lipid metabolism, when compared to NALM- 6 and NALM- $6 / \mathrm{H}$.

Cancer cells reprogram lipid metabolism during their malignant progression [12]. Enzymes in de novo FAS pathway, including ACLY, ACC and FASN, are upregulated in numerous cancers [12]. ACLY occupies a privileged position at the crossroads of the metabolism of cancer cells by linking both the glycolysis and lipid metabolism, having been found overexpressed in many aggressive cancers, and might play an important role in cancer relapse [33-35]. The researches on acute myeloid leukemia (AML) showed that low expression of ACLY is associated with favorable prognosis [36, 37]. On the contrary, our results showed that the ACLY and p-ALCY reduced in NALM-6/HDR. ACC is the first rate-limiting enzyme for FAS, which plays a critical role in leukemia progression [38]. ACC was initially considered as an oncoprotein [39], but recent papers showed that ACC might act as a tumor suppressor $[38,40]$. ACC1 may protect mice of AML models from leukemia death [38]. Our results also support that ACC might be a tumor suppressor, for the expression of ACC was reduced in NALM-6/ HDR obviously with no change in NALM-6/H. FASN, the only human lipogenic enzyme available for de novo FAS, has been widely reported to promote cancer progression [41, 42]. Upon hypoxic stress, different cancer cells had different cell-type-specific regulation of FASN, increased, decreased or unaffected [42]. A recent paper reported that FASN was upregulated in relapsed ALL patients; moreover, FASN inhibition may help to overcome glucocorticoid resistance [43]. FASN inhibition may sensitize AML cells to differentiation therapy [13]. On the contrary, our results showed that hypoxic stress induced FASN expression in NALM-6/H; however, FASN was reduced in GC resistant NALM-6/HDR cells. To be used in metabolic pathways, fatty acid must be activated by ACSLs, which convert free fatty acid to acyl-CoA [12]. ACSL1 may play a potential oncogenic role in colorectal and breast cancer and play a potential tumor suppressor in lung cancer [44]. AceCS1 catalyzes the conversion of acetate to CoA to acetyl-CoA and promote the FAS. Cancer cells display an up-regulated capability to utilize acetate [45]. Our results showed that ACSL1 and AceCS1were reduced in both NALM-6/HDR and NALM-6/H, which might be a stress reaction to hypoxia. Therefore, the results on GC resistant NALM-6/HDR and GC sensitive NALM-6/H may raise some new points about the roles of de novo FAS in relapsed/refractory leukemia. The relative low expression of ACLY, ACC, and FASN in GC-resistant NALM-6/HDR cells pointed out that targeting FAS might not a good idea for certain patients of relapsed/refractory leukemia.
Reprogramming of carbohydrate metabolism, particularly increased glycolysis, has been recognized as a hallmark of cancer [46] and plays a key role in cancer progression in different cancers $[8,10,47]$, which forms the basis of tumor imaging by positron emission tomography. Targeting glycolytic metabolism has become a potent therapeutic strategy to suppress cancer progression [14, 48]. Hypoxic stress may influence the energy metabolism and then induce glycolysis, which may contribute to chemoresistance [14, 31, 49]. Our results showed that hypoxic stress did not induce the expression of AMPK and p-AMPK. On the contrary, the expression ratio of p-AMPK and AMPK reduced in NALM-6/HDR and NALM-6/H. AMPK plays a paradoxical dual role in ALL survival and progression [49-51]. Here, decreased expression of AMPK and p-AMPK might contribute to GC resistance in NALM-6/HDR. NALM-6/HDR showed a decreased HKII and an increased LDHA in vitro or in vivo. NALM-6/H showed an increased Glut-1, LDHA and p-LDHA. These results suggest that AMPK and glycolysis pathway may not be a therapeutic target in GC resistant NALM-6/HDR. A recent paper reported that cancer cells preferred to uptake glutamine while myeloid cells in tumor microenvironment (TME) took up the most glucose [52]. Therefore, targeting glycolysis may enhance or impair tumor-related inflammation by disrupting the metabolic reprogramming of immune cells in TME, but not cancer cells [52]. A program of mTORC1-driven uptake of glutamine may suppress the expression of glycolysis-related genes and glucose metabolism in cancer cells [52]. We observed mTOR pathway was inhibited in NALM-6/HDR cells. Chronic and prolonged hypoxic exposure results in repression of mTORC1 signaling [53]. Initially, most researchers reported that mTOR signaling activation may contribute to chemoresistance and ALL progression $[17,23,54]$. On the contrary, a recent paper showed that activation of mTORC1 pathway may help suppress the drug resistance of T-ALL in hypoxic niches [55]. It is intriguing that while AMPK functions as an antagonist of mTOR [56]; both AMPK and mTOR signaling pathways were inhibited in NALM-6/HDR cells, which is consistent with the findings in CEM-C7/ HDR [6]. The orchestration of the cellular metabolism is not conducted by a single leader; the complex interplay between AMPK, mTOR, and other signaling network help to meet the conflicting self-requirement cancer cells [56]. Therefore, the relative low expression of AMPK and mTOR pathway is a distinct feature of NALM-6/HDR, which might be another key point to understand the mechanisms of GC resistance in ALL [6], and NALM-6/ HDR may provide a novel model that represents a subtype of GC-resistant B-ALL cells. 


\section{Conclusions}

Here, we constructed a new GC-resistant B-ALL cell line by mimicking the clinical setting in vivo. Compared with its parental cell line, NALM-6, the novel cell line, NALM-6/HDR, has a low expression of GR, a common feature of GC-resistant ALL cells. Moreover, NALM-6/ HDR has some distinct characters, including depression in AMPK, mTORC1, glycolysis and FAS pathway, which may hint that the previous therapeutic strategies, such as targeting AMPK, mTORC1, glycolysis and FAS pathway, could not reverse the GC resistant, or even induce some subtype of ALL aggravation. In addition, NALM-6/ HDR got cross-resistance to Ara-C. Therefore, NALM-6/ HDR may represent a novel cell type in B-ALL patients who acquired GC and Ara-c resistance during the treatment. NALM-6/HDR may serve as valuable in vitro and in vivo tools for further investigation on the potential mechanisms and therapeutic targets of relapsed/refractory B-ALL, especially the roles of the hypoxic TME in $\mathrm{GC}$ resistance.

\section{Abbreviations}

ALL: Acute lymphoblastic leukemia; ACC: Acetyl-CoA carboxylase; ACLY: ATP-citrate lyase; AceCS1: Acetyl-CoA synthetase; ACSL1: Long-chain acyl-CoA synthetase 1; AML: Acute myeloid leukemia; BM: Bone marrow; Dex: Dexamethasone; FAS: Fatty acid synthesis; FASN: Fatty acid synthase; GCs: Glucocorticoids; GR: Glucocorticoid receptor; PDL: Population doubling level; STR: Short tandem repeat; Td: Doubling time; TME: Tumor microenvironment.

\section{Supplementary Information}

The online version contains supplementary material available at https://doi. org/10.1186/s12935-021-02335-7.

Additional file 1: Fig. S1. Immunophenotypic characteristics of NALM-6/ HDR cell line. The immunophenotype was analyzed using a FACSCalibur flow cytometer. NALM-6/HDR and NALM-6 displayed identical immunophenotype with CD10, CD19, CD22, CCD79a and HLA-DR positive.

Additional file 2: Fig. S2. Venn diagram and DEGs analysis on NALM6, NALM-6/H, and NALM-6/HDR. a Venn diagram was used to display expressed gene between samples. b Based on the gene expression level, PossionDIS algorithms was used to detect the DEGs. X axis represented the sample. Y axis represented the DEGs.

Additional file 3: Fig. S3. Heatmap of DEGs and the DEGs in metabolism pathway between NALM-6 and NALM-6/HDR cells. a X axis represented the sample, NALM-6 and NALM-6/HDR. Y axis represented the DEGs. The color represents the log 10 transformed gene expression level. The dark color means the high expression level while the light color means the low expression level. $\mathbf{b}$ The metabolic functional enrichment results of NALM-6 compared with NALM-6/HDR after hierarchical clustering were shown in the table.

\section{Acknowledgements}

We are grateful to Dr. Ji Zhang and Dr. Yufang Wang for helping us complete the experiments.

\section{Authors' contributions}

YL performed a part of the research. CZ designed a part of the research, helped to analyze the data and wrote the paper. LG designed the research, performed a part of the research, analyzed the data and wrote the paper. All authors read and approved the final manuscript.

Funding

This work was supported by Sichuan Science and Technology Program of China (Grant No. 2021YFH0062), and the Fundamental Research Funds for the Central Universities (Grant No. SCU2019C4005).

\section{Availability of data and materials}

The datasets used and analyzed during the current study are available from the corresponding author on a reasonable request.

\section{Declarations}

\section{Ethics approval and consent to participate}

This study was approved by the Research Institute Animal Ethics Committee of West China Second University Hospital (Chengdu, China). All animal care was in compliance with the guidelines established by the internal Institutional Animal Care and Use Committee and Ethics Committee guidelines of Sichuan University.

\section{Consent for publication}

All authors have seen the manuscript and approved to submit to the journal. The material has not been published or is not under active consideration by another journal.

\section{Competing interests}

The authors declare no competing financial interests.

\section{Author details}

${ }^{1}$ Laboratory of Hematology/Oncology, Department of Pediatrics, Key Laboratory of Birth Defects and Related Diseases of Women and Children (Sichuan University), Ministry of Education, West China Second University Hospital, Sichuan University, No.20, Section 3, Renmin South Road, Chengdu 610041, People's Republic of China. ${ }^{2} J o i n t$ Laboratory of West China Second University Hospital, Sichuan University and School of Life Science, Fudan University for Pulmonary Development and Disease, Chengdu 610041, China. ${ }^{3} \mathrm{NHC}$ Key Laboratory of Chronobiology, Sichuan University, Chengdu 610041, China. ${ }^{4}$ Academic Affairs Department, West China Hospital/West China School of Medicine, Sichuan University, Chengdu, China.

Received: 22 July 2021 Accepted: 11 November 2021

Published online: 25 November 2021

References

1. Pui CH, Yang JJ, Hunger SP, Pieters R, Schrappe M, Biondi A, et al. Childhood Acute Lymphoblastic Leukemia: Progress Through Collaboration. J Clin Oncol. 2015;33:2938-48.

2. Inaba H, Pui CH. Glucocorticoid use in acute lymphoblastic leukaemia. Lancet Oncol. 2010;11:1096-106.

3. Ceppi F, Cazzaniga G, Colombini A, Biondi A, Conter V. Risk factors for relapse in childhood acute lymphoblastic leukemia: prediction and prevention. Expert Rev Hematol. 2015;8:57-70.

4. Coley HM. Development of drug-resistant models. Methods Mol Med. 2004;88:267-73.

5. Watson MB, Lind MJ, Cawkwell L. Establishment of in-vitro models of chemotherapy resistance. Anticancer Drugs. 2007;18:749-54.

6. Gu L, Zhang G, Zhang Y. A novel method to establish glucocorticoid resistant acute lymphoblastic leukemia cell lines. J Exp Clin Cancer Res. 2019;38:269.

7. Petit C, Gouel F, Dubus I, Heuclin C, Roget K, Vannier JP. Hypoxia promotes chemoresistance in acute lymphoblastic leukemia cell lines by modulating death signaling pathways. BMC Cancer. 2016;16:746.

8. Alexa-Stratulat T, Pešić M, Gašparović AČ, Trougakos IP, Riganti C. What sustains the multidrug resistance phenotype beyond $A B C$ efflux transporters? Looking beyond the tip of the iceberg. Drug Resist Updat. 2019:46:100643. 
9. Kaspers GJ, Pieters R, Van Zantwijk CH, Van Wering ER, Van Der Does-Van Den Berg A, Veerman AJ. Prednisolone resistance in childhood acute lymphoblastic leukemia: vitro-vivo correlations and cross-resistance to other drugs. Blood. 1998;92:259-66.

10. Faubert B, Solmonson A, DeBerardinis RJ. Metabolic reprogramming and cancer progression. Science. 2020. https://doi.org/10.1126/science.aaw5473.

11. Butler LM, Perone Y, Dehairs J, Lupien LE, de Laat V, Talebi A, et al. Lipids and cancer: emerging roles in pathogenesis, diagnosis and therapeutic intervention. Adv Drug Deliv Rev. 2020;159:245-93.

12. Matsushita Y, Nakagawa H, Koike K. Lipid metabolism in oncology: why it matters, how to research, and how to treat. Cancers (Basel). 2021:13:474.

13. Humbert M, Seiler K, Mosimann S, Rentsch V, Sharma K, Pandey AV, et al. Reducing FASN expression sensitizes acute myeloid leukemia cells to differentiation therapy. Cell Death Differ. 2021. https://doi.org/10.1038/ s41418-021-00768-1.

14. Yoshida GJ. Metabolic reprogramming: the emerging concept and associated therapeutic strategies. J Exp Clin Cancer Res. 2015;34:111.

15. Bloomfield CD, Smith KA, Peterson BA, Munck A. Glucocorticoid receptors in adult acute lymphoblastic leukemia. Cancer Res. 1981;41:4857-60.

16. Wandler AM, Huang BJ, Craig JW, Hayes K, Yan H, Meyer LK, et al. Loss of glucocorticoid receptor expression mediates in vivo dexamethasone resistance in T-cell acute lymphoblastic leukemia. Leukemia. 2020;34:2025-37.

17. Martelli AM, Evangelisti C, Chappell W, Abrams SL, Bäsecke J, Stivala F, et al. Targeting the translational apparatus to improve leukemia therapy: roles of the PI3K/PTEN/Akt/mTOR pathway. Leukemia. 2011;25:1064-79.

18. Simioni C, Martelli AM, Zauli G, Vitale M, McCubrey JA, Capitani S, et al. Targeting the phosphatidylinositol 3-kinase/Akt/mechanistic target of rapamycin signaling pathway in B-lineage acute lymphoblastic leukemia: An update. J Cell Physiol. 2018;233:6440-54.

19. MacLeod RA, Nagel S, Scherr M, Schneider B, Dirks WG, Uphoff CC, et al. Human leukemia and lymphoma cell lines as models and resources. Curr Med Chem. 2008;15:339-59.

20. Quentmeier H, Pommerenke C, Dirks WG, Eberth S, Koeppel M, MacLeod R, et al. The LL-100 panel: 100 cell lines for blood cancer studies. Sci Rep. 2019;9:8218.

21. Drexler HG, Quentmeier H. The LL-100 cell lines panel: tool for molecular leukemia-lymphoma research. Int J Mol Sci. 2020;21:5800.

22. Greenstein S, Ghias K, Krett NL, Rosen ST. Mechanisms of glucocorticoid-mediated apoptosis in hematological malignancies. Clin Cancer Res. 2002;8:1681-94.

23. Olivas-Aguirre M, Torres-López L, Pottosin I, Dobrovinskaya O. Overcoming glucocorticoid resistance in acute lymphoblastic leukemia: repurposed drugs can improve the protocol. Front Oncol. 2021;11:617937.

24. Tissing WJ, Meijerink JP, den Boer ML, Pieters R. Molecular determinants of glucocorticoid sensitivity and resistance in acute lymphoblastic leukemia. Leukemia. 2003;17:17-25

25. Gruber G, Carlet M, Türtscher E, Meister B, Irving JA, Ploner C, et al. Levels of glucocorticoid receptor and its ligand determine sensitivity and kinetics of glucocorticoid-induced leukemia apoptosis. Leukemia. 2009;23:820-3.

26. Xiao H, Ding Y, Gao Y, Wang LM, Wang H, Ding L, et al. Haploinsufficiency of NR3C1 drives glucocorticoid resistance in adult acute lymphoblastic leukemia cells by down-regulating the mitochondrial apoptosis axis, and is sensitive to Bcl-2 blockage. Cancer Cell Int. 2019;19:218.

27. Zawydiwski R, Harmon JM, Thompson EB. Glucocorticoid-resistant human acute lymphoblastic leukemic cell line with functional receptor. Cancer Res. 1983:43:3865-73.

28. Beesley AH, Weller RE, Senanayake S, Welch M, Kees UR. Receptor mutation is not a common mechanism of naturally occurring glucocorticoid resistance in leukaemia cell lines. Leuk Res. 2009;33:321-5.

29. Wilson WR, Hay MP. Targeting hypoxia in cancer therapy. Nat Rev Cancer. 2011;11:393-410.

30. Deynoux M, Sunter N, Hérault O, Mazurier F. Hypoxia and hypoxia-inducible factors in leukemias. Front Oncol. 2016;6:41.

31. Lee P, Chandel NS, Simon MC. Cellular adaptation to hypoxia through hypoxia inducible factors and beyond. Nat Rev Mol Cell Biol. 2020;21:268-83.

32. Koczula KM, Ludwig C, Hayden R, Cronin L, Pratt G, Parry H, et al. Metabolic plasticity in CLL: adaptation to the hypoxic niche. Leukemia. 2016;30:65-73.

33. Icard P, Wu Z, Fournel L, Coquerel A, Lincet H, Alifano M. ATP citrate lyase: A central metabolic enzyme in cancer. Cancer Lett. 2020;471:125-34.
34. Carrer A, Trefely S, Zhao S, Campbell SL, Norgard RJ, Schultz KC, et al. Acetyl-CoA metabolism supports multistep pancreatic tumorigenesis. Cancer Discov. 2019;9:416-35.

35. Icard LH. The reduced concentration of citrate in cancer cells: an indicator of cancer aggressiveness and a possible therapeutic target. Drug Resist Updat. 2016;29:47-53.

36. Wang J, Ye W, Yan X, Guo Q, Ma Q, Lin F, et al. Low expression of ACLY associates with favorable prognosis in acute myeloid leukemia. J Transl Med. 2019;17:149.

37. Basappa J, Citir M, Zhang Q, Wang HY, Liu X, Melnikov O, et al. ACLY is the novel signaling target of PIP2/PIP3 and Lyn in acute myeloid leukemia. Heliyon. 2020;6:e03910.

38. Ito H, Nakamae I, Kato JY, Yoneda-Kato N. Stabilization of fatty acid synthesis enzyme acetyl-CoA carboxylase 1 suppresses acute myeloid leukemia development. J Clin Invest. 2021;131:e141529.

39. Svensson RU, Parker SJ, Eichner LJ, Kolar MJ, Wallace M, Brun SN, et al. Inhibition of acetyl-CoA carboxylase suppresses fatty acid synthesis and tumor growth of non-small-cell lung cancer in preclinical models. Nat Med. 2016;22:1108-19.

40. Rios Garcia M, Steinbauer B, Srivastava K, Singhal M, Mattijssen F, Maida A, et al. Acetyl-COA carboxylase 1-dependent protein acetylation controls breast cancer metastasis and recurrence. Cell Metab. 2017;26:842-55.e5.

41. Röhrig F, Schulze A. The multifaceted roles of fatty acid synthesis in cancer. Nat Rev Cancer. 2016;16:732-49.

42. Munir R, Lisec J, Swinnen JV, Zaidi N. Lipid metabolism in cancer cells under metabolic stress. Br J Cancer. 2019;120:1090-8.

43. Ghaeidamini Harouni M, Rahgozar S, Rahimi Babasheikhali S, Safavi A, Ghodousi ES. Fatty acid synthase, a novel poor prognostic factor for acute lymphoblastic leukemia which can be targeted by ginger extract. Sci Rep. 2020;10:14072.

44. Chen WC, Wang CY, Hung YH, Weng TY, Yen MC, Lai MD. Systematic analysis of gene expression alterations and clinical outcomes for long-chain acylcoenzyme a synthetase family in cancer. PLoS ONE. 2016;11:e0155660.

45. Pandey SK, Yadav S, Temre MK, Singh SM. Tracking acetate through a journey of living world: evolution as alternative cellular fuel with potential for application in cancer therapeutics. Life Sci. 2018;215:86-95.

46. Ward PS, Thompson CB. Metabolic reprogramming: a cancer hallmark even warburg did not anticipate. Cancer Cell. 2012;21:297-308.

47. Mosier JA, Schwager SC, Boyajian DA, Reinhart-King CA. Cancer cell metabolic plasticity in migration and metastasis. Clin Exp Metastasis. 2021. https://doi.org/10.1007/s10585-021-10102-1.

48. Abdel-Wahab AF, Mahmoud W, Al-Harizy RM. Targeting glucose metabolism to suppress cancer progression: prospective of anti-glycolytic cancer therapy. Pharmacol Res. 2019;150:104511.

49. Herzig S, Shaw RJ. AMPK: guardian of metabolism and mitochondrial homeostasis. Nat Rev Mol Cell Biol. 2018;19:121-35.

50. Kishton RJ, Barnes CE, Nichols AG, Cohen S, Gerriets VA, Siska PJ, et al. AMPK is essential to balance glycolysis and mitochondrial metabolism to control T-ALL cell stress and survival. Cell Metab. 2016;23:649-62.

51. Grimaldi C, Chiarini F, Tabellini G, Ricci F, Tazzari PL, Battistelli M, et al. AMPdependent kinase/mammalian target of rapamycin complex 1 signaling in T-cell acute lymphoblastic leukemia: therapeutic implications. Leukemia. 2012;26:91-100.

52. Reinfeld BI, Madden MZ, Wolf MM, Chytil A, Bader JE, Patterson AR, et al. Cell-programmed nutrient partitioning in the tumour microenvironment. Nature. 2021;593:282-8.

53. Wouters BG, Koritzinsky M. Hypoxia signalling through mTOR and the unfolded protein response in cancer. Nat Rev Cancer. 2008;8:851-64.

54. Inoki K, Kim J, Guan KL. AMPK and mTOR in cellular energy homeostasis and drug targets. Annu Rev Pharmacol Toxicol. 2012;52:381-400.

55. Fahy L, Calvo J, Chabi S, Renou L, Le Maout C, Poglio S, et al. Hypoxia favors chemoresistance in T-ALL through an HIF1a-mediated mTORC1 inhibition loop. Blood Adv. 2021;5:513-26.

56. Alers S, Löffler AS, Wesselborg S, Stork B. Role of AMPK-mTOR-Ulk1/2 in the regulation of autophagy: cross talk, shortcuts, and feedbacks. Mol Cell Biol. 2012;32:2-11.

\section{Publisher's Note}

Springer Nature remains neutral with regard to jurisdictional claims in published maps and institutional affiliations. 